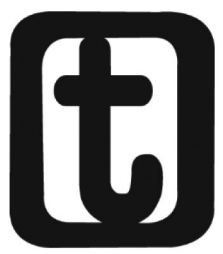

\title{
OS LIMITES À LIBERDADE NA SOCIEDADE DE CLASSES: algumas reflexões éticas
}

\author{
LIMITS TO FREEDOM IN CLASS SOCIETY: ethical reflexions
}

\author{
Luciana Ribeiro Paneghini'
}

\section{RESUMO}

Este trabalho objetiva analisar a assertiva "a sua liberdade termina quando começa a do outro", desmistificando o individualismo implícito à mesma. Para tanto, o artigo recorrerá à concepção marxiana de liberdade, buscando analisar quais os limites do capitalismo à liberdade, como valor ético humano, adquirido por meio do trabalho não alienado, fundamento ontológico do ser social. O reconhecimento da liberdade dos indivíduos sociais, enquanto sujeitos éticos e políticos, supõe a superação da cotidianidade e do moralismo. A liberdade, como um dos pressupostos do Código de Ética dos assistentes sociais, direciona o trabalho profissional cotidiano, no horizonte da emancipação humana.

PALAVRAS-CHAVE: Trabalho; Liberdade; Ética.

\section{ABSTRACT}

This paper aims to analyze the statement "your freedom ends where another's begins," demystifying the individualism in it. For make this, the article will resort to the marxian conception of freedom, trying to analyze what are the limits of capitalism to freedom, as a human ethical

1 Mestre em Serviço Social pela PUC-SP. Possui graduação em Serviço Social pela Faculdade Paulista de Serviço Social de São Caetano do Sul (2010). Atualmente é Analista de Promotoria I - assistente social do Ministério Público do Estado de São Paulo. 


\section{temporolis}

value, acquired through the work, ontological ground of being social. The recognition of social individuals' freedom, while political and ethical subjects, implies overcoming of everydayness and moralism. Freedom, as one of the requirements of social workers' Code of Ethics, directs the daily work on the horizon of human emancipation.

KEYWORDS: Work; Freedo; Ethics.

Submetido - 08/03/2015

Aceito - 03/06/2015

\section{Introdução}

Este trabalho é produto das discussões realizadas na disciplina Ética e Serviço Social, do Programa de Estudos Pós-Graduados em Serviço Social da Pontifícia Universidade Católica de São Paulo - PUC/ $\mathrm{SP}$, a partir da campanha antifumo, promovida pela universidade em tela, que teve como lema "a sua liberdade termina quando começa a do outro", frase que consta em dezenas de cartazes e faixas, afixados em todo o campus universitário. Os alunos da disciplina citada foram chamados a escrever trabalhos acadêmicos com este tema, desmistificando a concepção liberal de liberdade, com base no tratamento oferecido pelo legado marxiano e pela tradição marxista acerca desta categoria.

Com isto, o início do trabalho empreende a análise sobre a concepção, consoante a ontologia de Marx, do que sejam as categorias valor, liberdade, ética, sociabilidade, dentre outras. O trabalho, enquanto práxis, é o vetor pelo qual todas estas capacidades éticas foram se desenvolvendo, tornando possível, ainda, o desenvolvimento dos sentidos humanos e das normas e valores morais, com vistas ao desenvolvimento das sociabilidades e da convivência social. A análise aqui empreendida a respeito do trabalho, enquanto categoria fundante do ser social, tem início a partir de seu surgimento nas comunidades primitivas; o trabalho alienado, oriundo das sociedades baseadas na propriedade privada, será analisado, principalmente, na sociedade capitalista, em que o fetichismo, a reificação e a alienação dão novos sentidos (mais abstratos e idealizados) às concepções de liberdade. Após, o trabalho será concluído com uma reflexão acerca do cotidiano e da liberdade, enquanto um dos princípios éticos norteadores do trabalho do/a assistente social. 


\section{A liberdade como capacidade humano-genérica gerada pelo trabalho}

De acordo com Marx (2012 [1932]), o primeiro ato histórico dos seres humanos referiu-se à produção dos meios para a garantia de sua sobrevivência, em um mundo cuja natureza hostil os ameaçava. 0 homem, como ser natural, dependia de sua relação com a natureza para existir; porém, foi o trabalho que forneceu mediações para diferenciá-lo dos demais seres da natureza, tornando-o um ser social, ao transformar a natureza de acordo com suas necessidades.

Nas comunidades primitivas, antes de trabalharem sobre os elementos naturais, os seres humanos projetavam idealmente aquilo que queriam produzir, de acordo com o desenvolvimento de suas consciências ${ }^{2}$; assim, o pôr teleológico humano na atividade do trabalho foi o que diferenciou homens e mulheres dos animais, pois, diferentemente destes, que se relacionam com a natureza por meio de um padrão de intercâmbio instintivo e imediato para garantir a sua sobrevivência, as mediações estabelecidas pela atividade humana respondem às carências de maneira racional, consciente e projetiva, transformando os sentidos humanos no interior do processo de autoconstrução do ser social.

A práxis do trabalho, portanto, foi o que permitiu a homens e mulheres se constituírem como seres conscientes, universais e livres, capazes de produzirem sem a determinação das necessidades físicas. Aliás, Marx afirma que os seres humanos só podem produzir, verdadeiramente, de maneira criativa, quanto mais se afastarem de suas necessidades físicas prementes. (Marx, 2012 [1932]).

O trabalho, portanto, é condição insuprimível da vida humana e tem centralidade ontológica, na medida em que corrobora para o desenvolvimento de outras mediações como a arte, a sociabilidade, a linguagem, e outras. A necessidade de alterar a natureza, por meio do trabalho, permitiu o desenvolvimento da sociabilidade humana. Os primeiros homens e mulheres da história precisaram se dividir para a consecução do trabalho; tal divisão não era hierarquizada e nem

2 Ressalta-se que as primeiras experiências humanas com a natureza se deram por um viés instintivo, devido ao fato de os seres humanos, à época, não terem um grau de conhecimento mínimo sobre ela, o qual se fazia necessário para a sua alteração. Foi com o trabalho que os homens começaram a desenvolver, em suas consciências, os princípios e meios pelos quais a natureza seria modificada, para suprir as necessidades humanas. 


\section{temporalis}

resultava em ausência de autonomia dos sujeitos. Assim, Barroco (2010a) expressa:

[...] a sociabilidade é inerente a todas as atividades humanas, expressando-se no fato ontológico de que o homem só pode constituir-se como tal em relação com outros homens e em consequência dessa relação; ela significa reciprocidade 3 social, reconhecimento mútuo de seres de uma mesma espécie que partilham uma mesma atividade e dependem uns dos outros para viver. (BARROCO, 2010a, p. 22).

O trabalho e as relações que ele estabelece (dos homens e mulheres entre si e destes com a natureza) implicaram, ainda, no desenvolvimento de todos os sentidos humanos. Assim, a própria fome humana é saciada de distintas formas, a depender do grau do desenvolvimento histórico, econômico, social e cultural da humanidade. A descoberta e posterior compreensão do processo em que se produz o fogo, por exemplo, possibilitaram o cozimento da carne, que antes era comida crua. Possibilitaram, também, a fundição do ferro, para que fossem criados instrumentos para melhorar o simples ato de comer, como o garfo e a faca, por exemplo.

Ao modificar a natureza e, por conseguinte, desenvolver sua humanidade com o ato do trabalho, os seres humanos foram criando formas e instrumentos para facilitar a consecução de suas atividades. Nisto percebe-se o papel ativo da consciência na produção e, por este motivo, o trabalho constitui-se como uma mediação primária da vida social, em que a subjetividade se faz presente. A consciência tem papel ativo no trabalho e nas demais práxis humanas, na medida em que decorrem de intervenções práticas conscientes, que geram produtos até então inexistentes. Desta forma, como apontado acima, o trabalho só se efetiva por meio da capacidade teleológica humana, isto é, da projeção ideal das finalidades e meios para a sua consecução, o que demanda um grau de cooperação - possibilitada pela comunicação - de domínio sobre a natureza e de conhecimento a seu respeito e sobre os processos presentes no trabalho, capazes de transformá-la.

O duplo movimento realizado pelo trabalho - a saber, a atividade teleológica dos sujeitos, posta na atividade do trabalho, e a criação de uma nova realidade, oriunda da matéria transformada -

3 Grifo da autora. 
fazia com que os seres humanos se objetivassem no produto de seu trabalho. Conforme Barroco (2010a),

\begin{abstract}
Nesse processo, o sujeito se modifica e pode se autoreconhecer como sujeito de sua obra; a natureza se modifica por ter sido transformada pela ação do homem. O produto passa a ter uma existência independente do sujeito que o criou, mas não independente da práxis da humanidade, pois é resultante do acúmulo de conhecimento e da prática social dos homens. (BARROCO, 2010a, p. 24).
\end{abstract}

Este duplo movimento foi o que permitiu a construção da consciência histórica dos sujeitos. Com a ação transformadora possibilitada pelo trabalho, os sujeitos criaram alternativas, o que abriu possibilidade para a escolha entre elas. Tais escolhas eram realizadas consoante a valoração entre as diversas alternativas: escolhe-se o melhor meio e instrumento de trabalho, abrindo a possibilidade de realizar equiparações entre o que é bom ou mal, bonito ou feio, etc. Assim, as escolhas feitas pelos homens têm natureza valorativa, não necessariamente concernente aos valores morais. Por sua vez, a valoração das diferentes alternativas, com vistas à viabilização das escolhas, é avaliada em função do trabalho e das necessidades sociais. Assim, homens e mulheres passaram a criar novas necessidades e formas para sua satisfação, devido à complexificação dos sentidos humanos, inerente à ampliação das capacidades humano-genéricas.

Novas formas de práxis, possibilitadas pelo trabalho, como a educação, a arte, a filosofia, a moral, a ciência, a religião, e outras, chamadas de práxis interativas, propiciam também o desenvolvimento refinado do intelecto, da subjetividade e dos sentidos. Tais práticas sociais se distinguem da práxis material, uma vez que aquelas dizem respeito à finalidade de influir no comportamento e na ação de homens e mulheres, enquanto a práxis material refere-se ao controle e exploração da natureza, por parte dos seres humanos.

A emergência de alternativas e a possibilidade de escolhas de valor entre elas constituem a gênese da liberdade para Marx, uma vez que para ele a liberdade não é apenas a consciência dela ou da existência de escolhas, mas refere-se à "existência de alternativas e na possibilidade concreta de escolhas entre elas". (BARROCO, 2010a, p. 26). A liberdade não é apenas, portanto, um valor, mas uma capacidade humana decorrente e inseparável da atividade que a 


\section{temporalis}

objetiva. É "capacidade de escolha consciente dirigida a uma finalidade e capacidade prática de criar condições para realização objetiva das escolhas e para que novas escolhas sejam criadas". (BARROCO, 2010a, p. $27-28)^{4}$.

No entanto, a liberdade tem dois sentidos: uma é a liberdade negativa, que significa estar livre de algo (empenho em ações que rompam com os limites à liberdade) e, a outra, é a liberdade positiva, que denota estar livre para algo (ação voltada à objetivação, ampliação, defesa e estratégias de viabilização da liberdade). A liberdade, portanto, é uma capacidade humana, decorrente da objetivação do homem enquanto ser da práxis, que se realiza através do trabalho, entendido como fundamento ontológico do ser social.

O desenvolvimento da sociabilidade humana originou a moral, que responde à necessidade do estabelecimento de normas e deveres, com vistas à efetivação da convivência social. A moral é reproduzida por meio de hábitos e expressa valores e princípios socioculturais dominantes, de acordo com o contexto histórico. Ela tem função integradora, demanda aceitação subjetiva por parte dos sujeitos e diz respeito à mediação de valor entre sujeito e sociedade; a moral também produz novas mediações e influencia os sentimentos humanos, à medida que valora os comportamentos, reproduzindo-se por deveres. (Barroco, 2010b).

Ainda de acordo com Barroco (2010b), a capacidade do indivíduo de responder por seus atos em termos morais, mediante o discernimento entre valores (bom/mal; certo/errado), faz com que o mesmo se caracterize como sujeito ético-moral, portador do senso ou da consciência moral. A moral supõe o respeito aos demais, uma vez que, por meio da ação moral consciente, o sujeito assume a responsabilidade por seus atos e as decorrentes consequências, em sua vida e na vida dos outros. A ação ética só tem sentido quando o indivíduo supera o nível do "eu", encontrando-se com os demais, em uma relação de solidariedade, altruísmo e companheirismo. Há, contudo, ações sem implicação moral, ou seja, que não trazem consequências aos outros, como por exemplo, a escolha religiosa, a orientação sexual, o modo de se vestir etc. Tais atitudes só são percebidas como morais, ou seja, com implicações aos demais, quando seu julgamento se dá na perspectiva moralista.

4 Grifos da autora. 


\section{tempordils}

A ética, por sua vez, não pertence a nenhuma esfera específica da vida humana; ela se objetiva, teórica e praticamente, em "formas particulares e socialmente determinadas, como conexão entre o indivíduo singular e as exigências sociais e humano-genéricas" 5. (BARROCO, 2010a, p. 29).

A liberdade e a consciência, dentre outras capacidades éticas, são fundamentais para a objetivação ético-moral dos seres humanos, uma vez que estes precisam ser livres para escolher entre diversas alternativas, sem influências externas que os coajam a escolher de maneira diversa às suas necessidades ou vontades, ter controle sobre os seus impulsos e participação nas escolhas ético-morais, que realizam como sujeitos éticos.

\section{Os limites do capitalismo à liberdade}

Barroco (2010a), mencionando a historicidade implícita nos valores morais, aponta que, nas sociedades em que não havia a propriedade privada, o trabalho coletivo era tarefa de todos e os valores eram coletivistas; eram valorizados comportamentos que protegiam/ defendiam a comunidade, como a coragem, a responsabilidade, a disciplina, e outros. Os valores morais, portanto, respondiam às necessidades humanas, funcionando como sistema normativo, tendo em vista o atendimento às necessidades de sobrevivência.

Com o surgimento das sociedades de classe, a unidade de valores e necessidades comuns a todos os membros tornou-se impossível, embora as classes dominantes tentassem legitimar sua moral e abstrair as diferenças reais entre as classes antagônicas. $O$ desenvolvimento material e espiritual do gênero humano, possibilitado pelo desenvolvimento das forças produtivas e pelo controle humano sobre a natureza, permitiu a constituição da riqueza humana.

Porém, dependendo das condições históricas em que o trabalho se desenvolve, homens e mulheres se apropriam de maneiras diversificadas da riqueza socialmente produzida. Neste sentido, nas sociedades de classes e, mais precisamente, na sociedade capitalista, os/as trabalhadores/as se veem alienados/as não apenas do produto de seu trabalho, mas também, de seus meios e processos.

A objetivação de homens e mulheres através do trabalho dá

5 Grifos da autora. 


\section{temporalis}

lugar, na sociedade capitalista, a um trabalho estranhado, em que o seu produto também se configura como um poder estranho ao/à trabalhador/a. Desta forma, Marx (2012 [1932]) afirma

O operário torna-se tanto mais pobre quanto mais riqueza produz, quanto mais a sua produção cresce em poder e volume. $O$ operário torna-se uma mercadoria tanto mais barata quanto mais mercadoria cria. Com a valorização do mundo das coisas cresce a desvalorização do mundo dos homens em proporção direta. (MARX, 2012 [1932], p. 95).

Assim, a sociedade capitalista encerra uma contradição: se, por um lado, ela alavancou o desenvolvimento dos sentidos humanos e proporcionou a ampliação do crescimento cultural de homens e mulheres, devido ao desenvolvimento sem limites das forças produtivas, por outro lado, ela só o fez graças à exploração da força de trabalho daqueles/as que não detêm os meios de produção, tendo apenas a sua força de trabalho para sobreviver, pela burguesia.

O estranhamento gerado no trabalho também se dá entre os/as trabalhadores/as. O trabalho continua sendo social, mas os/ as trabalhadores/as não se reconhecem como seres de uma mesma classe, devido à fragmentação presente nos processos de trabalho e à alienação dos homens e mulheres em relação a eles. A riqueza que produzem não é acessível aos/às trabalhadores/as e os processos de trabalho em que se inserem, de maneira alienada, fazem com que a liberdade e a consciência destes homens e mulheres se objetivem de forma limitada, na medida em que eles/as não se apropriam de suas capacidades e de seus projetos. O trabalho, que antes era forma de manifestação da vida e que era meio para a objetivação dos seres humanos, hoje é um fim em si mesmo: é um instrumento de pura sobrevivência, em que os sujeitos se inserem para ganhar dinheiro, objeto pelo qual homens e mulheres têm acesso ao que é produzido no capitalismo.

Neste contexto, a sociedade de classes não possibilita o pleno desenvolvimento dos sujeitos sociais de forma equânime, uma vez que o acesso à riqueza socialmente produzida não se dá para todos. O dinheiro, por sua vez, é o elemento que tem a finalidade de tudo comprar. Assim, é ele quem tem a função de garantir alternativas a uma dada situação, movendo as escolhas. 
Uma grande parcela da sociedade detém uma parte diminuta da riqueza socialmente produzida, enquanto a outra se apropria da maior parte. Uma pesquisa do Instituto Brasileiro de Geografia e Estatística (IBGE) averiguou que, em 2012, 10\% dos mais ricos, no Brasil, detinham $42 \%$ da renda do País, enquanto os $40 \%$ mais pobres, concentravam apenas $13,3 \%$ desta renda. Nota-se, com isso, que uma grande parcela da população tem a sua liberdade restringida, uma vez que, ante a ausência de renda, as alternativas neste sistema se tornam escassas, não havendo como realizar escolhas que expressem uma liberdade que, na óptica marxista, está relacionada à existência de alternativas e às condições objetivas para materializá-las.

Embora esta seja apenas uma dimensão da (ausência de) liberdade, a sociedade burguesa ainda cria e recria formas de pensar e de se comportar, que potencializam a emergência de um novo significado de liberdade e de moral. É nesse sentido que a sociedade capitalista

[...] evidencia a pobreza e a riqueza do gênero humano, criando modos de ser em oposição, que coexistem pela afirmação e negação de si mesmos, o que não elimina a presença de um ethos dominante, que expressa as necessidades objetivas de (re)produção da vida social: o modo de ser capitalista ou ethos burguês. (BARROCO, 2010a, 157) .

Barroco (2010a), ainda, explicita que o ethos burguês implica na sociabilidade regida pela lógica mercantil, pela coisificação dos comportamentos e relações sociais, expressos na valorização da posse material, da competitividade e do individualismo. No capitalismo, inverte-se o sentido da existência humana: a reificação das relações humanas transforma sentimentos, escolhas, valores, capacidades e afetos em objetos, ao passo em que os objetos criados pelo capital são dotados de humanidade, ou seja, são fetichizados. As relações humanas passam a ser valorizadas pela sua utilidade, na medida em que só é bom aquilo que é útil e só é útil aquilo que responde à utilidade material, baseada na posse. O mesmo se dá com os valores morais: só têm validade aqueles valores que garantem o individualismo e a posse de bens, em detrimento da coletividade.

Este utilitarismo moral se dá na configuração de um ethos

6 Grifos da autora. 


\section{tompordlis}

superindividualista, em que o indivíduo se vê como proprietário de si próprio, eximindo-se de quaisquer relacionamentos contratuais com os demais, exceto aqueles que são de seu interesse; a sociabilidade humana, nestes termos, pauta-se em relações de mercado. (Macpherson apud Barroco, 2010).

A ideologia de que cada pessoa é proprietária de si faz com que os sujeitos se vejam como livres para satisfazer as suas necessidades e comportarem-se de tal modo que a sua autonomia não seja limitada. É neste contexto que surge a frase: "a liberdade de um termina quando a liberdade do outro começa”. Isto é, o indivíduo, marcado pela moral burguesa, apenas percebe sua liberdade quando se vê livre do outro, que é um limite à sua liberdade. A fragmentação possibilitada pelo ethos burguês supõe a divisão entre vida pública e vida privada, entre singularidade e a dimensão humano-genérica. Todas as dimensões da vida humana são vistas como somas isoladas e não como totalidade, o que faz com que os indivíduos possam assumir posições diferenciadas nas diversas dimensões de sua vida, sem prejudicar sua identidade. $O$ outro se torna um limite à sua liberdade individual e a reificação das relações sociais faz com que o outro seja percebido como um objeto descartável.

As relações sociais pautadas na moral burguesa não possibilitam espaços para a cumplicidade entre pares, ao contrário, o outro, o diferente, se torna um antagonista. Ao analisar a Declaração dos Direitos do Homem e do Cidadão pós-Revolução Francesa, que menciona a liberdade como o poder de fazer tudo o que não prejudique aos outros, Marx explicita o seguinte:

A liberdade equivale, portanto, ao direito de fazer e promover tudo que não prejudique a nenhum outro homem. O limite dentro do qual cada um pode moverse de modo a não prejudicar o outro é determinado pela lei do mesmo modo que o limite entre dois terrenos é determinado pelo poste da cerca. Trata-se da liberdade do homem como mônada isolada recolhida dentro de si mesma. (...) o direito humano à liberdade não se baseia na vinculação do homem com os demais homens, mas, ao contrário, na separação entre um homem e outro. Tratase do direito a essa separação, o direito do indivíduo limitado, limitado a si mesmo. A aplicação prática do direito humano à liberdade equivale ao direito humano à 


\section{tempordils}

propriedade privada.? (MARX, 2010, p. 49).

Desta forma, a frase "a sua liberdade termina quando começa a do outro" implica no seguinte: você só deve respeitar o outro porque ele tem a liberdade, assim como você, de ter o espaço dele. Este espaço é delimitado, por exemplo, pela lei antifumo (assunto que ensejou o tema deste trabalho), o que corrobora com a afirmação de Marx acima, sobre as instituições de leis burguesas que, praticamente, colocam cercas que delimitam o espaço de um e de outro. A própria instituição de algumas leis pode denotar que os indivíduos, sob a lógica burguesa, não têm respeitado às demais pessoas, necessitando de medidas repressivas que imponham limites à sua liberdade, vista pelo indivíduo burguês egoísta como ilimitada.

Não há, portanto, na assertiva "a sua liberdade termina quando começa a do outro", nenhuma mediação ética em que os sujeitos sejam percebidos como membros de um mesmo gênero humano, com capacidades e necessidades individuais que devem ser respeitadas, não nos termos da lógica burguesa que afirma o outro como limite, mas através de uma óptica fundada na solidariedade e na reciprocidade, em que os indivíduos sejam observados como sujeitos éticos. Com isto, nesta frase há uma oposição ao invés de uma posição integradora de valores humanos universais: a liberdade nunca é um valor absoluto, ela depende dos demais seres humanos para se objetivar.

É neste sentido, que Heller (1982) belissimamente explicita:

Toda pessoa tem a liberdade de não reconhecer nenhum valor moral. Mas, como já disse, isso não a ajuda a ser livre. Hegel tinha razão quando distinguiu entre liberdade e arbítrio. A liberdade é sempre liberdade para algo, e não apenas liberdade de algo. Se interpretarmos a liberdade apenas como o fato de sermos livres de alguma coisa, encontramo-nos no estado de arbítrio, definimo-nos de modo negativo. A liberdade é uma relação e, como tal, deve ser continuamente ampliada. O próprio conceito de liberdade contém o conceito de dever, o conceito de regra, de reconhecimento, de intervenção recíproca. Com efeito, ninguém pode ser livre se, em volta dele, há outros que não o são. (HELLER, 1982, p. 155) ${ }^{8}$.

7 Grifos do autor.

8 Grifos da autora. 


\section{temporalis}

A frase "a minha liberdade termina quando começa a do outro", portanto, explícita a ausência de reflexão ética sobre os seres humanos, enquanto sujeitos éticos, que devem assumir a responsabilidade por suas escolhas, não apenas pelas implicações à sua vida, mas à vida dos demais. Assim, a melhor alternativa - do ponto de vista ético-político crítico - para a redação dessa frase seria: "a minha liberdade começa e termina junto com a dos outros" ?.

\section{Considerações finais}

Conforme Barroco (2010b), a ética, considerada em seus fundamentos ontológicos, é parte da práxis interativa dos homens e contém uma série de potencialidades emancipadoras: torna o indivíduo responsável por suas escolhas, com fundamento na suposição de valores para avaliar as diferentes alternativas; é expressão da capacidade autolegisladora do ser social; propicia a ampliação da consciência dos seres humanos, estabelecendo vínculos sociais e o exercício da autonomia etc.

A moral, como forma de objetivação da capacidade ética do ser social, é parte da vida cotidiana, já que a reprodução das normas depende da repetição e do espontaneísmo para que se tornem hábitos e possam ser incorporados como costumes, possibilitando a integração social dos sujeitos. As prescrições morais devem ser legitimadas subjetivamente por homens e mulheres, para que sejam reproduzidas diante das situações cotidianas. No entanto, a partir do momento em que os seres humanos incorporam determinados comportamentos e os reproduzem de maneira acrítica e espontaneísta, percebe-se que, nem sempre, a realização de escolhas resulta no exercício da liberdade.

Assim, o modo capitalista de pensar e de se comportar se legitima através de normas e deveres morais, relacionados às necessidades de objetivação da sociabilidade mercantil, necessitando da ideologia dominante para se reproduzir, enquanto conjunto de ideias e valores que visam a favorecer a legitimação da ordem burguesa. Por meio de mediações complexas, a moral também é perpassada por interesses de classe e pela necessidade de reprodução de outros sistemas de dominação, interligados à dominação/exploração do capital sobre o trabalho. É assim que a moral burguesa cumpre a

9 Reflexão realizada pelo Prof. Dr. Antônio Carlos Mazzeo, na disciplina Fundamentos Filosóficos e a Questão do Método nas Ciências Sociais, em 8 de maio de 2014. 
função precisa de reproduzir a ideologia da classe dominante, não apenas pela imposição de normas que formam os sujeitos para assumirem a posição de trabalhadores/as ou de burgueses/as, mas, também, para dividir os/as trabalhadores/as por meio do machismo, racismo, homofobia, entre outros. Os preconceitos e a intolerância são decorrentes dos juízos provisórios, concernentes ao pensamento cotidiano, que é ultrageneralizador e pragmático. Estes juízos só são considerados preconceitos quando continuam a fundamentar o pensamento e as ações, mesmo quando refutados pela prática e pela teoria.

O preconceito, por sua vez, se torna moralismo quando as atividades e comportamentos são julgados, imediatamente, com fundamento na moral. É isso o que faz, por exemplo, com que uma mulher encare como natural que outras mulheres sejam estupradas, a depender da roupa com que elas estiverem vestidas. Mesmo no século XXI e após a refutação da ideia de que os homens possuiriam uma sexualidade incontrolável, algumas pessoas continuam acreditando que a culpa é da mulher, pela violência sexual sofrida, uma vez que se pautam na discriminação e no preconceito contra ela para reiterar valores moralistas que a oprimem e que dificultam a objetivação de sua liberdade enquanto sujeito. Uma mulher que expressa o preconceito contra outras mulheres, reiterando valores moralistas que cerceiam a liberdade destas (como a liberdade relacionada à escolha da roupa, por exemplo), está ainda mais longe de entender a sua própria situação, enquanto mulher e enquanto ser humano. Assim, o moralismo corrobora para a reificação da consciência das pessoas, possibilitando uma forma de alienação em que elas não se reconhecem nos seus pares, enquanto membros de um mesmo grupo oprimido.

Da mesma forma, os homens que oprimem as mulheres, por meio da violência sexista, estão também impregnados pelo moralismo e pelo preconceito contra a mulher (machismo), submetendo-as ao papel de objeto, que a tudo deve suportar. Assim, eles estão longe de perceberem a si e a estas mulheres como seres humanos: a cada vez que impõem dor e sofrimento a outro sujeito histórico, mais distantes eles estão de superar a sua cotidianidade alienada e sua existência reificada.

Para superar este estado de coisas, em que a moral é vista sob uma perspectiva utilitarista e moralista, se faz necessária a reflexão 


\section{temporalis}

ética, que supõe a suspensão da cotidianidade. Tal reflexão tem por objetivo a sistematização crítica da vida cotidiana, pressuposto para que sua organização se dirija para além das necessidades voltadas ao "eu", "ampliando as possibilidades de os indivíduos se realizarem como individualidades livres e conscientes". (BARROCO, 2010b, p. 55).

Enquanto categoria profissional, os/as assistentes sociais têm como direção ético-política hegemônica alguns princípios éticos que norteiam o seu trabalho junto à população usuária e que oferece, ainda, ditames éticos que orientam sua relação com os/ as demais profissionais com quem trabalham e com as instituições empregadoras. Estes princípios são preconizados pelo Código de Ética do/a Assistente Social, Resolução n² 273, de 13 de março de 1993, que ainda prevê normas para os direitos e as responsabilidades gerais dos/ as assistentes sociais, bem como as penalidades (quando as normas e princípios preconizados são violados pelos/as profissionais) e os processos éticos implícitos ao seu cumprimento.

Um dos princípios éticos que norteiam o trabalho do/a assistente social, conforme o referido Código de Ética, refere-se ao "reconhecimento da liberdade comovalorético central e das demandas políticas a ela inerentes - autonomia, emancipação e plena expansão dos indivíduos sociais". (CFESS, 1993). Assim, os/as assistentes sociais, em seu trabalho profissional, devem pautar a sua conduta no reconhecimento da liberdade dos sujeitos atendidos, impulsionando ou, ao menos, não restringindo a sua autodeterminação, enquanto sujeitos ético-políticos. Tal princípio, assim como o da democracia, fundamenta os demais valores presentes no Código, articulando-se, diretamente, com todos os outros princípios. (Barroco e Terra, 2012). Por sua vez, o valor de natureza humano-genérica mais central do Código de Ética é a emancipação, sendo que “(...) os demais princípios (valores) essenciais: a liberdade, a justiça social, a equidade e a democracia são simultaneamente valores e formas de viabilização da emancipação humana" (BARROCO in BARROCO e TERRA, 2012, p. 58).

Assim, o nosso projeto ético-político atual é direcionado pela intenção de ruptura com o conservadorismo, informando o nosso lugar a favor da democracia e na luta pela efetivação dos direitos humanos, ainda que na sociedade capitalista. Apesar disso, o Código de Ética também se vincula a um projeto ético-político que aponta para a direção da construção de uma nova ordem societária, em que os indivíduos poderão produzir livremente e tomar parte na 
produção social da humanidade, o que poderá possibilitar a expansão da liberdade dos sujeitos enquanto membros do gênero humano, a partir do reconhecimento dos demais como partícipes deste mesmo ente genérico.

\section{Referências}

BARROCO, Maria Lúcia S. Ética: fundamentos sócio-históricos. São Paulo: Cortez, 2010a.

. Ética e Serviço Social: fundamentos ontológicos. São Paulo: $\overline{\text { Cortez, } 2010 b .}$

; TERRA, Sylvia Helena. (Org.). Código de ética do/a assistente social comentado. São Paulo: Cortez, 2012.

CFESS. Conselho Federal de Serviço Social. Resolução n. 273, de 13 março de 1993. Institui o Código de Ética Profissional dos Assistentes Sociais e dá outras providências. Disponível em: <http://www.cfess. org.br/arquivos/CEP_1993.pdf>. Acesso em: 21 maio 2014.

HELLER, Agnes. Para mudar a vida: felicidade, liberdade e democracia. São Paulo: Brasiliense, 1982.

MARX, Karl. Sobre a questão judaica. São Paulo: Boitempo, 2010.

- Trabalho alienado, propriedade privada e comunismo. PAULO NETTO, José. (Org.). O leitor de Marx. Rio de Janeiro: Civilização Brasileira, 2012.

PESQUISA do IBGE revela que $10 \%$ mais ricos concentram $42 \%$ da renda no país. Terra-Notícias, 29 nov. 2013. Disponível em: <noticias.terra. com.br/brasil/politica/pesquisa-do-ibge-revela-que-10-mais-ricosconcentram-42-da-renda-no-pais,88e7433116492410VgnCLD2000000 ec6eboaRCRD.html>. Acesso em: 21 maio 2014. 
